\title{
Amor celeste e amor terrestre: o encontro de Alcibíades e Sócrates em 0 banquete, de Platão
}

G uilherme G utman

Neste texto realiza-se uma introdução à leitura de O banquete, de Platão, em especial de seu último trecho, ao qual corresponde o encontro de Alcibíades e Sócrates. Procurou-se ainda, indicar algumas discussões despertadas por esse diálogo platônico; principalmente aquelas que fazem referência às relações entre a filosofia, a literatura e a psicanálise.

Palavras-chave: Platão, Sócrates, Alcibíades, O banquete, amor 
Um dia em que se exercitava na luta e, pressionado pelo adversário, estava a ponto de ceder, abocanhou o braço que o imobilizava e fez menção de devorá-lo. O outro soltou-o, gritando: "Mordes como as mulheres, Alcibíades!" "Não, como os leões”, retrucou ele.

Plutarco

O banquete - obra de Platão (427-347 a.C.) que sobreviveu aos séculos; resistindo, a despeito de seu tema central, a ameaças sortidas, tais como a potencial censura dos monges e escrevinhadores (como especula Lacan, 1960-1961) ou as investidas dos primeiros críticos do platonismo - foi objeto de incontáveis comentários. Nestes, cada elemento presente no texto foi discutido de modo pormenorizado: sua autenticidade, as modificações que teria eventualmente sofrido, a veracidade histórica de seus personagens, a data de sua composição e, principalmente, o sentido de cada uma das frases que o compõem. ${ }^{1}$

Sendo assim tão numerosos os comentadores desse diálogo de Platão, torna-se difícil conceber a possibilidade de consenso em torno de algum desses temas. Ao que parece, se chega mais perto, senão do consenso, ao menos de certo acordo entre os estudiosos, quando se admite que $O$ banquete é a matriz de todos os discursos sobre o amor no Ocidente. Não poderia ser diferente, quando se concorda que não apenas este diálogo específico, mas todo o conjunto da obra deixada por Platão funciona como marco inaugural da própria filosofia ocidental. A propósito, é conhecida a frase de Alfred North Whitehead, segundo o qual a tradição filosófica europeia poderia ser considerada “uma série de notas de rodapé” de Platão.

$\mathrm{O}$ fato é que nos discursos presentes em $O$ banquete - especialmente no discurso do personagem Aristófanes - a sensibilidade contemporânea reconhece, no mito por ele recriado, algo muito característico do modo como apreendemos os sentimentos amorosos. Em seu discurso, notamos brotar de uma fábula fantástica e algo cômica, a expectativa de recompensa nos encontros afetivos:

1. Para um excelente apanhado das principais discussões em torno de $O$ banquete, sugerimos enfaticamente a leitura de Robin (1992); para uma base mais geral nos estudos platônicos, ver Gosling (1983), Grube (1970), Jaeger (2001), Koyré (1984) e Kraut (1996). Para aqueles que se iniciam nesses estudos, recomendamos especialmente Chaú (2002). 
Em primeiro lugar, três eram os gêneros da humanidade, não como agora, o masculino e o feminino, mas também havia mais um terceiro, comum a estes dois, do qual resta agora um nome, desaparecida a coisa; andrógino era então um gênero distinto (...). Depois, inteiriça era a forma de cada homem, com o dorso redondo, os flancos em círculo; quatro mãos ele tinha, e as pernas o mesmo tanto das mãos, dois rostos opostos um ao outro era um só, e quatro orelhas, dois sexos, e tudo o mais como desses exemplos se poderia supor. (...) Eram (...) de uma força e de um vigor terríveis, e uma grande presunção eles tinham; mas voltaram-se contra os deuses (...) Depois de laboriosa reflexão, diz Zeus: "Acho que tenho um meio de fazer com que os homens possam existir, mas parem com a intemperança (...) eu os cortarei a cada um em dois (...). Por conseguinte, desde que a nossa natureza se mutilou em duas, ansiava cada um por sua própria metade e a ela se unia (...). É então de há tanto tempo que o amor de um pelo outro está implantado nos homens, restaurador da nossa antiga natureza, em sua tentativa de fazer um só de dois e de curar a natureza humana. (189e, 190a-d, 191a, 191d)² (Platão, 1995, p. 125-129)

Todavia, o melhor talvez não seja tomar esse diálogo platônico como um início cronológico absoluto dos discursos sobre o amor; mas ao contrário, e como parece sugerir Kristeva (1988), antes como "uma história das atitudes e dos discursos amorosos que é, sem dúvida, o repositório mais voluptuoso da alma ocidental” (p. 81). A imagem de um "repositório de atitudes e discursos” desloca a questão anterioridade-posterioridade da obra de Platão em relação a todo o conjunto de teorias sobre o amor e de experiências amorosas, e sugere que em $O$ banquete temos uma espécie de ponto de passagem obrigatório sobre o tema. Anterior ou posterior, tudo o que, ligado ao amor, se diga ou faça deve partir ou chegar a esta obra máxima. ${ }^{3}$

2. Os números e letras entre parênteses correspondem ao sistema de referência mundialmente adotado para os trechos das obras de Platão. Como ensina Kraut, eles correspondem "à paginação da edição de Platão publicada em 1578 por Henri Estienne (c.1528/31-1598). Eles são chamados de páginas de Stephanus, a partir da forma latinizada de 'Estienne'” (1996, p. 30-31).

Doravante, usaremos esta notação para designar os trechos citados de Platão (sempre na edição referida na bibliografia).

3. Kristeva (1988) vai ainda mais longe, quando afirma que "desde que existe, a psique só fala e só toma forma em amor” (p. 81). Assim, o tratamento dado por Platão ao tema e a sua absorção pela posteridade, transbordam o tópico, a partir do momento em que o "amor" é a via privilegiada a partir da qual o psiquismo é entendido como tal.

De certa maneira, a posição de Kristeva irá ao encontro do desenvolvimento do conceito de “desejo" elaborado por Lacan a partir de $O$ banquete, conforme se verá adiante. 
Entre os tópicos massivamente estudados sobre $O$ banquete, está a origem

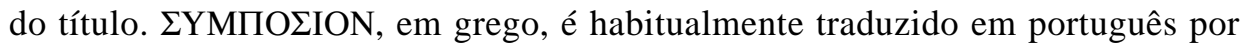

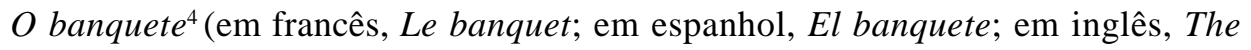
Symposium). De acordo com Mitchell (1993), a tradução literal do grego seria "bebendo junto" ou "a festa de beber". Como quer que se traduza, a presença do vinho (portanto, a presença de Baco ou Dionísio) era não só obrigatória, como central e sujeita a regras específicas: habitualmente o simposiarca estabelecia a quantidade de vinho que cada participante deveria obrigatoriamente beber. A bebida tinha uma função específica que era a de modular, de algum modo, os discursos que deveriam ser apresentados pelos convivas naquilo que deve ser entendido como o ponto alto - talvez não fosse exagero dizer, a razão de ser do encontro. Além da bebida e dos discursos, havia uma série de preliminares: o jantar, as libações, as preces, os cânticos... Mas visualizar um banquete na Grécia antiga como um evento apenas festivo, seria um erro de interpretação histórica. Como esclarece Robin (1992), havia então toda uma preocupação em que o encontro não tendesse a uma orgia; como sugerido em outro diálogo platônico - Leis - a regulamentação da bebida e das etapas do simpósio tinham um caráter fortemente moral.

É por essa razão que comentadores como Mitchell (1993) ficam intrigados com o fato de que se tenha escolhido como título desse diálogo, algo que faz referência explícita ao vinho e às suas regras no contexto de um banquete, quando exatamente nesse banquete abdicou-se da presença compulsória da bebida por uma razão, à primeira vista, trivial. No seguinte trecho, pode-se ler:

Reclinou-se Sócrates e jantou com os outros; fizeram as libações e, depois dos hinos ao deus e dos ritos de costume, voltam-se à bebida. Pausânias então começa a falar mais ou menos assim: Bem, senhores, qual o modo mais cômodo de bebermos? Eu por mim digo-vos que estou muito indisposto com a bebedeira de ontem, e preciso tomar fôlego - e creio que também a maioria dos senhores, pois estáveis lá; vede então de que modo poderíamos beber o mais comodamente possível. (...).

Ouvindo isso, concordam todos em não passar a reunia embriagados, mas bebendo cada um a seu bel-prazer. (176a-b, e)

Mas eis que, se de início o deus Dionísio sai pela porta dos fundos, ao final de $O$ banquete, ele retorna pela porta da frente; para entender plenamente as razões da presença-ausência do vinho nesse simpósio, será preciso esperar que,

4. De acordo com Robin (1992), To symposion seria a tradução mais correta do grego, sendo $O$ banquete, fruto de uma tradição que remonta a tradução latina: Convivium. 
após os discursos previstos, tenha vez o discurso de Alcibíades e a sua repercussão sobre Sócrates.

\section{Os personagens}

O modo como em $O$ banquete chega aos seus leitores aquilo que teria se passado naquele dia, é - engenho de Platão - bastante sinuoso.

$\mathrm{O}$ relato é feito pelo personagem Apolodoro a um outro personagem nomeado apenas de "companheiro" que acaba, por assim dizer, ocupando o lugar de cada leitor do diálogo (172-174a), posto que é a ele que Apolodoro se dirige ao longo de todo o texto.

Apolodoro relata ao seu companheiro, que há não muito tempo, quando caminhava de sua casa em Falero a Atenas, foi interpelado por Glauco que, tendo sabido que Apolodoro havia escutado um relato do simpósio, pedia que este fizesse uma narrativa do que teria então ouvido.

Apolodoro, por sua vez, teria escutado um relato do que teria se passado em O banquete, da boca de Aristodemo (cuja veracidade dos fatos é posteriormente confirmada pelo próprio Sócrates), ele sim, presente no encontro.

Assim, além da notável importância que o registro na memória ocupava na preservação dos discursos proferidos, vale notar que o relato final - que na composição de Platão nos chega pelas palavras de Apolodoro - está autorizado a um sem número de acréscimos, omissões e transcriações.

Aristodemo, então, como tantos outros, um jovem vivamente interessado nos passos e nas palavras de Sócrates, encontra-o, ao contrário de seu habitual, banhado e calçado, porque se dirigia à casa de Agatão - poeta, escritor de tragédias, festejado na ocasião por ter vencido o seu primeiro festival dramático, ${ }^{5}$ anfitrião de $O$ banquete e autor de um dos discursos que seria escutado no simpósio - e recebe o convite para acompanhá-lo.

Além de Agatão, de Sócrates, do convidado de última hora - Aristodemo (que não falou, mas apenas escutou), do já mencionado Aristófanes, participaram com discursos Fedro, Pausânias e Erixímaco.

Sabendo que cada um desses nomes evoca um personagem histórico, como separar o registro "autêntico” de cada um deles dos personagens ficcionais de Platão?

5. Para a importância dos festivais dramáticos, ver Jaeger (2001). 
A fronteira aí entre ficção e compromisso histórico dever ser relativizada para o bem de historiadores da filosofia e de literatos. Indubitavelmente, H. Bloom (2003, 2005) segue essa diretriz, mas se ele não leva muito a sério a demarcação do que seria o limite entre os domínios da literatura e da filosofia, no que diz respeito especificamente a Platão, suas investigações são algo tímidas. Bem sabemos quão longe Bloom é capaz de ir no que tange ao tema ${ }^{6}$ e, de qualquer forma, a despeito de sua economia sobre os gregos, ele mais uma vez parece acertar o alvo quando nota que “o Sócrates de Platão é a Ficção Suprema deste”7 (Bloom, 2005, p. 73), não interessando tanto, na obra platônica, distinguir onde acaba Sócrates e onde começa Platão.

Enfim, se $O$ banquete é certamente uma obra filosófica máxima, é também uma peça literária ímpar e de grandeza maior.

Quando a nossa leitura desse texto magnífico é iluminada também pela psicanálise - representada aqui por Brenkman, Kristeva e, especialmente, por Lacan - há ainda menos razões para insatisfação quanto ao caráter saudavelmente ambivalente de $O$ banquete: literatura ou filosofia? É que, como nota Brenkman (1982), a presença da literatura na obra de Platão promove uma estimada subversão das afirmações filosóficas presentes na obra. Caso a literatura não se amalgamasse à filosofia de forma tão especial neste diálogo platônico, o discurso de Sócrates soaria certamente brilhante, mas dogmático; teria toda a nobreza do discurso dos deuses, mas perderia em humanidade. A literatura aqui torna a filosofia platônica mais flexível e terrena, isto é, ela é tornada algo diferente do que seria, caso apresentada de outra forma. Do mesmo modo, o simpósio teria sido outro - mais calmo e fiel ao programa previamente estipulado - caso tivesse terminado antes do surgimento de Alcibíades. O pletórico Alcibíades contrapõe ao discurso temperado de Sócrates, não exatamente mais um discurso sobre o amor, mas um relato de suas experiências amorosas com Sócrates. Desta forma, temos “dois discursos incomensuráveis”, já que posicionados em degraus diferentes: o da descrição idealística do amor e o do discurso implicado do sujeito em suas próprias experiências e desejo. É portanto a entrada de Alcibíades em cena aquilo que

6. Sobre este tópico, ver Gutman (2008).

7. Neste ponto, a discussão de Bloom é sobretudo com aqueles que seguem a posição de um dos grandes comentadores de Platão - Gregory Vlastos - como, por exemplo, Kraut (1996), para quem o Sócrates dos diálogos iniciais seria o Sócrates histórico, enquanto nos diálogos intermediários e tardios (grupo do qual faria parte $O$ banquete), teríamos a transformação de Sócrates em Platão. Bloom, ao contrário, supõe que o Sócrates histórico é aquele presente em Xenofonte e que o Sócrates de Platão, como já se disse, é o seu personagem supremo. 
permitirá que $O$ banquete possa ser lido através de lentes psicanalíticas, as quais permitirão ver aquilo que se passa entre Sócrates e Alcibíades como da ordem da transferência.

\section{O amor celeste}

O discurso de Sócrates, certamente aquele sobre o qual recairiam as maiores expectativas, teria fechado a programação do simpósio, caso Alcibíades não tivesse aparecido de surpresa e colocado a coisa toda em termos muito diferentes.

Após a fala de Agatão, em mais uma elaboração engenhosa de Platão, Sócrates faz falar em seu lugar - já que desenvolve o seu discurso sob a forma de um relato daquilo que, quando jovem, teria escutado sobre o estatuto do amor uma mulher: Diotima. ${ }^{8}$ Antes, porém, de fazer dele a voz desta (ou vice-versa), interrogando Agatão, termina por postular que:

1. O amor é amor de algo (199e).

2. O amor é desejo ${ }^{9}$ do que não se tem (200a).

3. O amor deseja o Belo e o Bom (201a-b).

Ao finalmente fazer Diotima falar em seu discurso, Sócrates propõe uma natureza intermediária para o amor. Sua proposição se fundamenta na junção de suas asserções anteriores: se o amor é “desejo do que não se tem” e se caso o que se deseja é o Belo e o Bom; então o amor não seria bom nem belo? Não, teria respondido Diotima; o amor comunica céu e terra: o amor seria, então, um "daimon" com o poder de "interpretar e transmitir aos deuses o que vem dos homens, e aos homens o que vem dos deuses” (202e).

Começa a surgir nesse ponto a ideia do amor como uma possibilidade de aceder às formas do Bom e do Belo. É também nesse privilegiado local de entidade

8. A presença espiritual de Diotima e a manobra do discurso socrático também foi objeto de várias especulações. Em uma delas, propõem-se que Diotima estaria, para Sócrates, em um lugar idealizado, porque dessexuado; nesta acepção, Diotima corresponderia, de algum modo, à possibilidade terrena mais alta de acesso às formas do Bem (Kristeva, 1988, p. 93-4).

9. Deve-se notar que há neste ponto um deslizamento entre "amor" e "desejo", possibilidade corroborada pela definição do verbete "Eros” em Peters, 1983, p. 81-5).

10. Definido por Peters (1983) como se segue: "presença ou entidade sobrenatural algures entre um deus (theos) e um herói” (p. 47). 
intermediadora, que Platão colocará a filosofia. ${ }^{11}$ Naturalmente, tal posição dá aos filósofos um lugar de extrema importância num dado mundo, como aquele que ele projeta em outro de seus diálogos: A República.

Esta ideia ganha o seu desenvolvimento pleno em Sócrates com aquilo que se convencionou chamar de “a escada do amor", ${ }^{12}$ imagem na qual está contida a ideia de que cada cidadão poderia galgar os estágios que, quando certos, levariam à contemplação das formas essenciais do Belo/Bom.

No texto de Platão, essa ideia é formulada como se segue:

Eis, com efeito, em que consiste o proceder corretamente nos caminhos do amor ou por outro se deixar conduzir: em começar do que aqui é belo e, em vista daquele belo, subir sempre, como que servindo-se de degraus, de um só para dois e de dois para todos os belos corpos, e dos belos corpos para os belos ofícios, e dos ofícios para as belas ciências até que das ciências acabe naquela ciência, que de nada mais é senão daquele próprio belo, e conheça enfim o que em si é belo. Neste ponto da vida, meu caro Sócrates, se é que em outro mais, poderia o homem viver, a contemplar o próprio belo. Se algum dia o vires, não é como ouro ou como roupa que ele te parecerá ser, ou como os belos jovens adolescentes, a cuja vista ficas agora aturdido (...). Que pensamos então que aconteceria, disse ela, se a alguém ocorresse contemplar o próprio belo, nítido, puro, simples, e não repleto de carnes humanas, de cores e outras muitas ninharias mortais, mas o próprio divino belo pudesse ele em sua forma única contemplar? (...) Não consideras, disse ela, que somente então, quando vir o belo com aquilo com que este pode ser visto, ocorrer-lhe-á produzir não sombras de virtude, porque não é em sombra que estará tocando, mas reais virtudes, porque é no real que estará tocando? (211c-e, 212a)

É preciso notar que a promessa aqui não é pequena, mas inversamente, a maior recompensa que o platonismo logrou conceber: a contemplação da própria essência do Belo. ${ }^{13}$

11. Em determinado ponto de $O$ banquete, lê-se: "Uma das coisas mais belas é a sabedoria, e o Amor é amor pelo belo, de modo que é forçoso o Amor ser filósofo e, sendo filósofo, estar entre o sábio e o ignorante” (204b).

Esta ideia é destacada por Jaspers (1962), que escreve: “(No pensamento filosófico) experimentamos as nossas vacilações, os nossos altos e baixos. Nós caímos, nós falhamos, nós vivemos mais uma vez os movimentos do amor. Porque o amor é como a filosofia, um being-between” (p. 45).

12. Por exemplo, em A. Bloom (1996).

13. É claro que a referência aqui é a uma das ideias mais poderosas da metafísica platônica: “eidos”, habitualmente traduzida por "forma”. Ver Peters (1983). 
Mas como já foi dito, a entrada de Alcibíades nos reserva surpresas, fazendo dessa escada - que purificada degrau a degrau até o seu topo imaculado - um ideal regulador da vida terrena. Tal é a percepção de Kristeva, da inversão dessa erótica:

No interior do próprio texto platônico, em elevação alada rumo ao Supremo Bem através da visão calorosa, evanescente, efervescente do Belo. Eros possessão destruidora - transforma-se nesse quarto século antes de nossa era num Pteros, pássaro idealizador tomado no movimento ascendente da alma, certamente decaída, mas que se lembra infalivelmente de ter voado mais alto. (...)

À alma platônica alada, sucederá a alma plotiniana com seu espelho narcísico. Esta minirrevolução nos legará uma nova concepção do amor: amor centrado no em si, embora aspirado para o Outro ideal. (1988, p. 81-2)

Kristeva aponta essa espécie de internalização de um ideal, como uma etapa fundamental na direção da constituição de subjetividades. Contudo, para extrairmos consequências ainda mais interessantes das leituras psicanalíticas de $O$ banquete, de fato será preciso entrar naquilo que se passa entre Sócrates e Alcibíades.

\section{$\mathrm{O}$ amor terrestre}

A chegada de Alcibíades à casa de Agatão é marcada pelos signos do excesso, do ruído e do impacto sobre os presentes.

Súbito a porta do pátio, percutida, produz um grande barulho, como de foliões, e ouve-se a voz de uma flautista. Agatão exclama: Servos! Não ireis ver? Se for algum conhecido, chamai-o; se não, dizei que não estamos bebendo, mas já repousamos.

Não muito depois ouve-se a voz de Alcibíades no pátio, bastante embriagado, e a gritar alto, perguntando onde estava Agatão, pedindo que o levassem para junto de Agatão. Levam-no então até os convivas a flautista, que o tomou sobre si, e alguns outros acompanhantes, e ele se detém à porta, cingido de uma espécie de coroa tufada de hera e violetas, coberta a cabeça de fitas em profusão, e exclama: Senhores! Salve! (212c-e)

Todos ali conhecem Alcibíades; ou melhor, todos conhecem Alcibíades. E se a sua chegada ao simpósio é como a de um Dionísio que descendo da morada dos deuses à terra exigindo o que lhe é de direito - a presidência do encontro e vinho em proporções adequadas a um banquete no qual esteja presente - não é segredo para ninguém que a sua presença não inspira apenas festejos, mas tam- 
bém medo e respeito devidos à sua força, poder e presença sanguínea. Se Agatão se prontifica a bem recebê-lo é, em parte, porque Alcibíades também é um ilustre membro de certa elite, porque Agatão certamente teme estar em falta com alguém que pode ser mesmo cruel e, porque não, também porque como anfitrião, espera que o seu banquete seja inesquecível e, é inegável, a presença de Alcibíades sempre acrescentará algum calor a uma reunião.

O personagem histórico Alcibíades pode ser bem conhecido no retrato que Plutarco dele constrói em Vidas paralelas. ${ }^{14}$ Ali temos todos os principais ingredientes que dele fazem uma figura ímpar: a beleza extraordinária, a impetuosidade, a violência, o gosto pelas coisas boas e belas, os grandes feitos, a popularidade e o caráter duvidoso.

Alcibíades surpreendeu-se genuinamente quando descobriu que Sócrates estava lá; ao lado de Agatão. Seu desconcerto é secundado por Sócrates com uma reação que caberia definir como verdadeiro pavor, supostamente em função da paixão violenta, possessiva e do comportamento agressivo de Alcibíades em relação a ele. ${ }^{15}$

Não sem antes reivindicar dois litros de vinho servidos em um porta-gelo, usurpar o lugar de simposiarca de Erixímaco, Alcibíades propõe uma mudança no programa: não mais um elogio do amor, mas um elogio do outro, cabendo ao próprio Alcibíades, louvar Sócrates. ${ }^{16}$

Antes de entregarmos o texto de Platão ao leitor, vale reunir algumas observações.

14. Lacan (1960-1961-a) também se serve do relato de Plutarco e, a partir daquilo que lê, imagina Alcibíades (devemos lembrar que o Seminário 8 transcorreu nos dois primeiros anos da década de 1960) como "um personagem que seria, digamos, o sr. Kennedy, um Kennedy que ao mesmo tempo tivesse sido um James Dean” (p. 32). Deixamos a cargo do leitor imaginar que outros dois personagens contemporâneos representariam hoje o presidente Kennedy e Dean.

15. "E Sócrates: Agatão, vê se me defendes! Que o amor deste homem se me tornou um não pequeno problema. Desde aquele tempo, com efeito, em que o amei, não mais me é permitido dirigir nem o olhar nem a palavra a nenhum belo jovem, senão este homem, enciumado e invejoso, faz coisas extraordinárias, insulta-me e mal retém suas mãos da violência” (213 c-d). Vale ainda notar que a ira de Alcibíades não tem qualquer relação com alguma espécie de abuso ou transgressão que regula a relação entre o erômenos e o erastes (sobre as regras desse formato específico de relacionamento, é suficiente consultar Foucault, 1990). A queixa de Alcibíades se dirige ao fato de que Sócrates teria recusado todos os seus termos de sedução.

16. A partir desse ponto, se inicia o trecho de $O$ banquete que está reproduzido neste número da Revista. De qualquer modo, exortamos o leitor a travar contato, na primeira oportunidade, com o texto de Platão na íntegra. 
Primeiro, se o que foi dito sobre a "escada do amor" for retomado, se verá que há aí o que Lacan chamou de "o deslizamento de todo o discurso de Diotima” (1960-1961a, p. 131), qual seja, a passagem do desejo daquilo que é belo ao desejo do Belo, como forma ou essência. Quando Alcibíades adentra a cena, e propõe a reversão do elogio do amor ao elogio do outro, ele desliza no sentido oposto ao de Diotima, saindo do "ultra-mundo"17 e falando de alguma coisa mais terrena, que poderá parecer, à sensibilidade contemporânea, mais próxima de como se experimenta o amor, isto é, de um em relação a outro. ${ }^{18}$

Segundo, e já modificando um pouco os termos de nossa primeira observação: a proposta subversiva de Alcibíades, no que tange ao programa do simpósio, não deve ser encarada como uma descida de degrau da escada do amor, de volta ao amor de um só; fosse assim, seria como trocar ouro por cobre. O amor de Alcibíades por Sócrates não ocupa nenhum dos degraus dessa escada; mas estaria, numa imagem espacial, meio ao lado ou por trás da escalada proposta por Diotima em seu discurso.

Além disso, o amor de Alcibíades não é de um para um, ${ }^{19}$ mas, ao contrário, envolve necessariamente um terceiro; e mais: talvez o seu amor nem seja dirigido propriamente a Sócrates, mas a algo que ele possuiria - agalma - sem que, necessariamente, Sócrates saiba exatamente de que é feito esse objeto que é a causa do desejo de Alcibíades.

Terceiro, e finalmente, no comentário de Lacan, aquilo que se passa entre Sócrates e Alcibíades pode ensinar muito sobre os mecanismos transferenciais em jogo no processo analítico. Nesta via, quando Sócrates diz a Alcibíades que tudo aquilo de tão extraordinário que parece dirigido a ele, Sócrates, teria como alvo

17. Expressão de Lacan (1960-1961a), que complementa com o seguinte: “É preciso, realmente, apontar de saída em que mundo ele (Alcibíades) nos faz mergulhar de novo, de repente, depois da grande miragem fascinante. Digo mergulhar de novo, pois esse mundo não é o ultramundo, é o mundo, simplesmente, onde sabemos, afinal, como se vive o amor. Todas essas belas histórias, por fascinantes que pareçam, basta um tumulto, uma entrada de bêbados, para nos devolver a ele, como ao real” (p. 136).

18. Como coloca Ferrari (1996), Alcibíades está “in love”, e não discursando sobre aquilo que ele, sozinho, pensa ser o amor.

19. A relação dual, sugere Lacan (1960-1961a), aparece, de fato, no discurso de Diotima: “Aquele que empreende a escalada em direção ao amor procede por uma via de identificação e igualmente, se quiserem, de produção, sendo nisso ajudado pelo prodígio do belo. Ele chega a ter nesse belo seu próprio termo, e identifica-o à perfeição da obra do amor. Existe ali uma relação biunívoca, que tem por fim a identificação com este soberano bem” (p. 140). Encontramos nesse trecho ecos das elaborações de Kristeva (1988) sobre os mecanismos identificatórios referidos acima.

Rev. Latinoam. Psicopat. Fund., São Paulo, v. 12, n. 3, p. 539-552, setembro 2009 
Agatão, estaríamos diante de todas as características de uma interpretação. Isso porque, sabedor das coisas do amor, Sócrates entende que os agalmata que Alcibíades diz terem despertado o seu desejo, não estão na verdade dentro de Sócrates - não é propriamente algo que lhe pertença. Se Alcibíades ouviu Sócrates e ouvindo as suas próprias palavras ditas por um outro, encantou-se; o sileno Sócrates tem no seu interior um vazio, ainda que modelado segundo condições muito especiais (Lacan, 1998a, 1998b, 2003).

A causa do desejo de Alcibíades está nenhures, mas ele não deixará jamais de buscá-lo.

\section{Referências}

BLoom, A. Amor e amizade. São Paulo: Mandarim, 1996.

Blom, H. Gênio: os 100 autores mais criativos da história da literatura. Rio de Janeiro: Objetiva, 2003.

. Onde encontrar a sabedoria. Rio de Janeiro: Objetiva, 2005.

BREnkman, J. The other and the one: psychoanalysis, reading, The Symposium. In: Felman, S. (ed.). Literature and Psychoanalysis. The question of reading: Otherwise. London: Johns Hopkins, 1982. p. 396-456.

Chau, M. Introdução à história da Filosofia: dos pré-socráticos a Aristóteles. São Paulo: Companhia das Letras, 2002.

Ferrari, G. R. F. Platonic Love. In: Kraut, R. (ed.). The Cambridge Companion to Plato. Cambridge: Cambridge University Press, 1996.

Foucault, M. História da sexualidade 2: o uso dos prazeres. Rio de Janeiro: Graal, 1990.

GosLing, J. C. B. Plato. London: Routledge \& Kegan Paul, 1983.

Grube, G. M. A. Plato's Thought. London: Methuen, 1970.

Gutman, G. Freud, Lear \& Bloom: algumas notas sobre leitura e psicanálise. Alea. v. 10, n. 1, p. 108-120, 2008. Disponível em: <http://www.scielo.br>.

JAEger, W. W. Paidéia: a formação do homem grego. São Paulo: Martins Fontes, 2001.

JASPers, K. Plato and Augustine. New York: Harcourt, Brace \& World, 1962.

Koyre, A. Introdução à leitura de Platão. Lisboa: Presença, 1984.

Kraut, Richard. Introduction to the Study of Plato. In: Kraut, R. (ed.). The Cambridge Companion to Plato. Cambridge: Cambridge University Press, 1996.

KRISTEVA, J. Histórias de amor. Rio de Janeiro: Paz e Terra, 1988. 
LaCAN, J. (1960-1961a). O seminário. Livro 8. A transferência. Rio de Janeiro: Zahar, 1992.

. (1960-1961b). Le séminaire. Livre VIII. Le transfert. Paris: Seuil, 1991.

. Subversão do sujeito e dialética do desejo no inconsciente freudiano. In:

Escritos. Rio de Janeiro: Zahar, 1998a. p. 807-42.

. Do "trieb” de Freud e do desejo do psicanalista. In: Escritos. Rio de Janeiro:

Zahar, 1998b. p. 865-68.

. Proposição de 9 de setembro de 1967 sobre o psicanalista da Escola. In:

Outros Escritos. Rio de Janeiro: Zahar, 2003. p. 248-64.

Mitchell, R. L. The Hymn to Eros: a reading of Plato's Symposium. Lanham:

University Press of America, 1993.

Peters, F. E. Termos filosóficos gregos: um léxico histórico. Lisboa: Fundação

Calouste Gulbenkian, 1983.

Platão. O banquete; ou Do amor. Rio de Janeiro: Bertrand Brasil, 1995.

Plutarco. Vidas paralelas. São Paulo: Paumape, 1991. v. 2.

Robin, L. Notice. In: Platon Oeuvres Complètes. Tome IV - 2a partie: Le Banquet. Paris: Les Belles Lettres, 1992.

Singer, I. The Nature of Love: Plato to Luther. Chicago: The University of Chicago Press, 1984.

\section{Resumo}

(Amor celeste y amor terrestre: el encuentro de Alcibíades y Sócrates en El banquete, de Platón)

En este texto se realiza una introducción a la lectura de El Banquete, de Platón; especialmente del último trecho, que corresponde al encuentro de Alcibíades y Sócrates. Se procuró señalar algunas de las discusiones que este diálogo platónico suscita; principalmente aquellas que hacen referencia a las relaciones entre la filosofía, la literatura y el psicoanálisis.

Palabras claves: Platón, Sócrates, Alcibíades, El Banquete, amor

(Amour céleste et amour terrestre: la rencontre entre Alcibiade et Socrate dans Le Banquet de Platon)

Ce texte est une introduction à la lecture du Banquet de Platon mettant l'accent sur la dernière partie qui décrit la rencontre entre Alcibiade et Socrate. Nous y 
exposons quelques réflexions inspirées par ce dialogue de Platon, notamment au sujet des liens entre la philosophie, la littérature et la psychanalyse.

Mots clés: Platon, Socrate, Alcibiade, Le Banquet

(Celestial love and earthly love: the encounter between Alcibiades e Socrates in Plato's The Banquet)

This essay is meant as an introduction to Plato's Banquet and, more specifically, to the last part, concerned with the encounter between Alcibiades and Socrates. The essay also explores a few thoughts brought up by this Platonic dialogue, especially those that point toward the relationships among philosophy, literature and psychoanalysis.

Key words: Plato, Socrates, Alcibiades, symposium, love

Citação/Citation: Gutman, G. Amor celeste e amor terrestre: o encontro de Alcibíades e Sócrates em O banquete, de Platão. Revista Latinoamericana de Psicopatologia Fundamental, São Paulo, v. 12, n. 3, p. 539-552, set. 2009.

Editor do artigo/Editor: Prof. Dr. Paulo José Carvalho da Silva

Recebido/Received: 30.7.2009 / 7.30.2009 Aceito/Accepted: 4.8.2009 / 8.4.2009

Copyright: ( 2009 Associação Universitária de Pesquisa em Psicopatologia Fundamental/ University Association for Research in Fundamental Psychopathology. Este é um artigo de livre acesso, que permite uso irrestrito, distribuição e reprodução em qualquer meio, desde que o autor e a fonte sejam citados/This is an open-access article, which permits unrestricted use, distribution, and reproduction in any medium, provided the original author and source are credited.

Financiamento/Funding: $\mathrm{O}$ autor declara não ter sido financiado ou apoiado/The author has no support or funding to report.

Conflito de interesses: $\mathrm{O}$ autor declara que não há conflito de interesses/The author declares that has no conflict of interest.

\section{GUILHERME GUTMAN}

Psicanalista; psiquiatra; doutor em Saúde Coletiva pelo Instituto de Medicina Social da Universidade do Estado do Rio de Janeiro - UERJ (Rio de Janeiro, RJ, Brasil); professor do Departamento de Psicologia da Pontifícia Universidade Católica do Rio de Janeiro - PUC-Rio (Rio de Janeiro, RJ, Brasil)

Rua Visconde de Pirajá, 595/905 - Ipanema

22410-003 Rio de Janeiro, RJ.

Fone: (21) 3026-0064 / 9106-7009

e-mail: guilhermegutman@gmail.com 